\title{
Functional and oncological outcomes of salvage external beam radiotherapy following robot-assisted radical prostatectomy in a Canadian cohort
}

\author{
Khaled Ajib ${ }^{1,2}$; Marc Zanaty ${ }^{1,2}$; Mansour Alnazari ${ }^{1,2}$; Emad Rajih ${ }^{1,2}$; Pierre-Alain \\ Hueber $^{1}$; Mila Mansour ${ }^{1}$; Roger Valdivieso ${ }^{1}$; Cristina Negrean ${ }^{1}$; Pierre I. \\ Karakiewicz $^{1}$; Daniel Taussky ${ }^{3,4}$; Guila Delouya ${ }^{3,4}$; Assaad El-Hakim ${ }^{1,2}$; Kevin C. \\ Zorn $^{1}$ \\ ${ }^{1}$ Section of Urology, Department of Surgery, Centre Hospitalier de l'Université de Montréal; ${ }^{2}$ Division \\ of Robotic Urology, Department of Surgery, Hôpital du Sacré Cœur de Montréal; ${ }^{3}$ Department of \\ Radiation Oncology, Centre Hospitalier de l'Université de Montréal, Hopital Notre- \\ Dame; ${ }^{4} \mathrm{CRCHUM}$-Centre Hospitalier de Recherche du Centre Hospitalier de l’Université de Montréal; \\ Montreal, QC, Canada
}

Cite as: Can Urol Assoc J 2017 Dec. 1; Epub ahead of print. http://dx.doi.org/10.5489/cuaj.4641

Published online December 1, 2017

\begin{abstract}
Introduction: We sought to determine the impact of salvage radiotherapy (SRT) on oncological and functional outcomes of patients with prostate cancer after biochemical recurrence (BCR) following robot-assisted radical prostatectomy (RARP).
\end{abstract}

Methods: Data of 70 patients with prostate cancer treated with SRT after developing BCR were retrospectively analyzed from a prospectively collected RARP database of 740 men. Oncological (PSA) and functional (pads/day, International Prostate Symptom Score [IPSS], and Sexual Health Inventory for Men [SHIM]) outcomes were reported at six, 12, and 24 months after RT and adjusted for pre-SRT status. Results: Men who underwent SRT had a mean age, prostate-specific antigen (PSA), and time from radical prostatectomy (RP) to RT of 61.8 years $(60.1-63.6), 0.5 \mathrm{ng} / \mathrm{ml}$ (0.2-0.8), and 458 days (307-747), respectively. Freedom from biochemical failure (FFBF) post-SRT, defined as a PSA nadir $<0.2 \mathrm{ng} / \mathrm{mL}$ was observed in $89 \%$, 93\%, and $81 \%$ at six, 12, and 24 months, respectively. Undetectable PSA was observed in $14 \%, 35 \%$, and $40 \%$ at the same time points, respectively. There was no significant difference in urinary continence post-SRT $(\mathrm{p}=0.56)$. Rate of strict continence $(0$ pads/day) was $71 \%$ at 24 months compared to $78 \%$ pre-SRT. Mean IPSS at six, 12 , and 24 months were 3.4, 3.6, and 3.6, respectively compared to pre-RT score of 3.3 
$(\mathrm{p}=0.61)$. The mean SHIM score pre-SRT was comparable at all time points following treatment $(\mathrm{p}=0.86)$.

Conclusions: In this unique Canadian experience, it appears that early SRT is highly effective for the treatment of BCR following RARP with little impact on urinary continence and potency outcomes.

\section{Introduction}

Prostate cancer is considered to be the most common cancer in men. There are an estimated 151,360 new cases each year. ${ }^{1}$ Robot-assisted radical prostatectomy (RARP) has been adapted increasingly in Canada. In the USA, nearly $80 \%$ of all prostatectomies are performed with this technique. ${ }^{1}$

Post-prostatectomy radiotherapy (RT) is commonly used to maximize oncologic outcomes in patients. Adjuvant radiotherapy (ART) is used with certain pathological features including the pathological stage and margin status. In the absence of adjuvant radiotherapy, the 5-year risk of biochemical recurrence is 50 to $75 \%$ in high-risk patients. ${ }^{2}$ However, salvage radiotherapy (SRT) is used in cases with elevated PSA post operatively or biochemical recurrence. The European guidelines state that early SRT provides a possibility of cure for patients with an increasing or persistent PSA after RP. Roughly, $60 \%$ of patients who are treated before the PSA level rises to $>0.5 \mathrm{ng} / \mathrm{mL}$ will achieve an undetectable PSA level. Therefore, patients will have an $80 \%$ chance of being progression-free 5 years later. ${ }^{3}$ Bradely et al states that the outcomes of SRT are positively affected when initiated at lower PSA levels. ${ }^{4}$ It is well established that radiotherapy has an impact on the prognostic and functional status of the patient. One study demonstrated that the delayed administration of RT has a positive effect on erectile dysfunction and urinary continence post RP. ${ }^{5}$ The aim of this study is to question and determine the real impact of early SRT on the patients' oncological outcome in relation to their PSA levels. Moreover, it will discuss the effect of early SRT on the functional status of the patients.

\section{Methods}

\section{Patient characteristics}

After Institutional-review board approval, a prospectively collected database of patients who underwent RARP for localized prostate cancer at our institution included 740 men between 2006 and 2014 was retrospectively reviewed. All men had RARP using our standardized surgical approach. ${ }^{6}$

\section{Salvage radiation therapy}

Among these, 70 node-negative patients underwent standardized SRT at one of 2 academic centers performed by dedicated uro-radiation oncologists. The patients undertook 33 sessions of radiotherapy (66 Gy) with an intensity of 2 Gy per day. Patients were followed up for a period of 2 years. Patients with adjuvant radiotherapy or usage of any hormonal therapy were not included for the analysis. Our study retrospectively analyzes data from these patients. 


\section{Definitions and statistical analysis}

The oncological outcome was related to the PSA level, which was measured pre and post RT. Biochemical failure after SRT was defined as serum PSA rising above the post-treatment nadir to a level of $0.2 \mathrm{ng} / \mathrm{mL}$ or more with a confirmatory value. With no international consensus for the definition of post prostatectomy incontinence, ${ }^{7}$ in our study, continence was clinically assessed using the number of pads used per day. Patients who use no pads or 1 security pad (PRN) were considered as continent. However, patients using 1 or more pads were considered incontinent. With respect to the lower urinary tract symptoms, the validated IPSS score was used including the QOL score. Moreover, both the validated erection hardness score (EHS) and the SHIM scores were used to evaluate potency. ${ }^{8}$ Outcomes were reported at 6 , 12, and 24 months after SRT. Additionally, adjustment of these values was done and compared with pre-RT status. Categories were compared using Chi-square test and Fisher exact test for categorical variables. A p-value $<0.05$ was considered as clinically significant.

\section{Results}

This study included 70 patients who had undergone RARP and salvage radiotherapy. Table 1 demonstrates the baseline characteristics of the men participating in our study. Patients are categorized according to pre-RT PSA value $(<$ or $\geq 0.2 \mathrm{ng} / \mathrm{ml})$. The mean age, PSA value prior to SRT and time from RP to RT were 61 years, 0.50 ng/mL [CI (0.21 - 0.79)], and 458 days [CI (307 - 747)], respectively. Nerve sparing techniques were bilateral, unilateral and non-nerve sparing in $48.57 \%, 15.71 \%$ and $35.71 \%$, respectively. The average PSADT among our population was 15.97 months [CI (11.97 - 19.97)]. Mean post surgical CAPRA-S score in the cohort was 4.14 [CI $(2.18-6.11)$ ] with a range from 1 to 8 (Mode: 4$) .62 .9 \%$ of men had a PSA $\geq 0.2$ $\mathrm{ng} / \mathrm{ml}$ before initiation of SRT. Pathological features of all 70 are summarized in table 1. The majority of men had pathological Gleason score of $7(3+4)(38.57 \%)$. It shows that $67.14 \%$ (47) of the patients had positive surgical margins the majority of which had a pathological stage of T3 (74\%). SRT was initiated at a PSA $<0.2 \mathrm{ng} / \mathrm{ml}$ in $44.68 \%$ of the men with positive surgical margins. $16 \%$ of the patients had documented seminal vesicle invasion.

Patients were followed up for a period of 24 months. After 24 months, 42 out of $52(80.77 \%)$ patients had a PSA less than $0.2 \mathrm{ng} / \mathrm{ml}$. 21 out of these 42 men (50\%) had an undetectable PSA of $0 \mathrm{ng} / \mathrm{ml}$ at 24 months. $41 \%$ of the patients with extracapsular extension had a PSA value $<0.2 \mathrm{ng} / \mathrm{ml}$ before RT. This value increased up to $80 \% 24$ months post RT. With respect to surgical margins, the percentage of patients with positive surgical margins with a PSA value $<0.2 \mathrm{ng} / \mathrm{ml}$ is $44 \%$ and $81 \%$ pre and post RT, respectively ( $\mathrm{p}$-value $=0.80$ ).

The Kaplan-Meyer curve for both populations is shown in figure 1. The first curve (green line) is for the population with a pre-RT PSA of $<0.2 \mathrm{ng} / \mathrm{ml}$ that included 26 patients. 3 out of 26 men had a PSA $>0.2 \mathrm{ng} / \mathrm{ml} 2$ years after SRT. To add, $27 \%$ of the patients who started RT at a PSA level $<0.2 \mathrm{ng} / \mathrm{ml}$ had an 
undetectable PSA 2 years later. The 44 patients with a pre-RT PSA $\geq 0.2 \mathrm{ng} / \mathrm{ml}$ are demonstrated in the second curve (red line).

Tables 2 and 3 assess the urinary and sexual functional outcome respectively of men undertaking radiotherapy. Table 2 demonstrates that $78.5 \%$ (55) of men were continent at the time of radiotherapy. Through out the follow-up of these 55 men, continence was maintained in 37 men with a follow-up to 24 months. Only 5 out of these 55 patients started to use 1 pad 24 months after RT. With respect to possible detrusor impact of SRT, the IPSS was also studied. The mean value was 3.6 after radiotherapy compared to 3.38 before radiotherapy (all p-values NS). Table 2 also demonstrates that there is no significant relationship between radiotherapy and the quality of life of the patients (p-value $=0.98$ ).

The relation between SRT and erection is reported in table 3. Analysis demonstrates that there appears to be no significant relation between SRT and EHS ( $\mathrm{p}$-value $=0.98$ ). Among the 25 men who had an EHS $\geq 3$ (potent) pre RT, 21 remained in the study beyond 12 months, 19 of which continued to report an EHS $\geq 3$. At 24 months, the 16 patients (originally 25 pre-RT) who remained in the study had an $\mathrm{EHS} \geq 3$.

The overall mean SHIM score of the men was 8.82 before radiotherapy compared to 8.18, 24 months after RT (p-value $=0.66$ ). 2 years after initiation of radiotherapy, $86 \%$ of men had a SHIM score less than 21 compared to $82 \%$ before radiotherapy (table 3). When sub analysis of the pre-SRT men with EHS $\geq 3$ was conducted, the mean SHIM for these 25 men were 18.32, 15.8, 16.62, 16.76 at preSRT, 6 months, 12 months, and 24 months respectively (p-value $=0.6$ ).

\section{Discussion}

RARP has gained rapid adoption in the United States and globally since its description in early 2002. Over the past decade, RARP has been demonstrated as a safe procedure with acceptable oncological and functional outcomes with benefits of shorter hospital stay, convalescence and blood loss as the forefront of reduced morbidity. ${ }^{9}$

The current guidelines define BCR as a rising PSA after surgery with two documented consecutive rises over the value of $0.2 \mathrm{ng} / \mathrm{ml} .{ }^{10}$ Radiotherapy represents a curative therapeutic option that can be offered to men with postoperative detectable PSA. ${ }^{11}$ The purpose behind the modality of SRT is to reduce the PSA values and to maintain PSA recurrence free status. ${ }^{12}$ The 3-year BCR rate after RARP and SRT was $36 \%$ comparable to the rates post open or laparoscopic prostatectomies. ${ }^{13}$

Kwon et al indicated that there are significant outcomes for patients who receive SRT for BCR after primary RP. They highlight the significance of certain predictors that might lead to a favorable outcome. Some of the recognized predictors of success were: low pre-RT PSA values, longer PSADT before SRT, concomitant ADT administration, and positive surgical margins. ${ }^{14}$

The early administration of salvage RT to patients with BCR after RP has a good long-term outcome. ${ }^{15}$ A pooled analysis published in the European Urology 
Journal has shown that the 5-year biochemical recurrence free survival in patients receiving early salvage RT was $71 \% .{ }^{14}$ Gandaglia et al described certain clinical features that may benefit from early SRT. They talked about patients with Gleason score $\geq 8, \mathrm{pT} 3 \mathrm{~b} / 4$, and lymph node invasion. ${ }^{16}$ On the other hand, a study published in the Clinical Journal of Oncology that included 2460 patients with a median follow up of 5 years stated that early SRT at low PSA levels after RP has a better outcome in patients. They reported improvement in freedom from biochemical failure and distant metastasis rates. ${ }^{17}$ In our study RT was initiated at an average PSA level of $0.5 \mathrm{ng} / \mathrm{ml}$ (CI 0.2 - 0.79]). The figures have shown that the PSA value is less than $0.2 \mathrm{ng} / \mathrm{ml}$ in $93 \%$ of the patients 12 months after RT (p-value $<0.001$ ). This value reaches $81 \%$ after 24 months, knowing that the total number of patients at the end of the study is 52 due to loss of follow up. Such values prove the oncological success of early SRT, which is defined as a PSA nadir of less than $0.2 \mathrm{ng} / \mathrm{ml}$. In cases of pT3, capsule rupture, or seminal vesicle invasion with a PSA less than $0.1 \mathrm{ng} / \mathrm{ml}$ post RP, the European guidelines offer two options. Those options are initiation of adjuvant radiotherapy after urinary function recovery, or monitoring the patient and offering SRT before the PSA exceeds $0.5 \mathrm{ng} / \mathrm{ml}^{3}$ In our study, the percentage of patients with a PSA $<0.2 \mathrm{ng} / \mathrm{ml} 24$ months after RT is $80 \%, 81 \%$, and 55\% for patients with extracapsular extension, positive surgical margins, and seminal vesicle invasion respectively compared to $41 \%, 45 \%$, and $36 \%$ pre-RT.

To add, there is a better cancer control with administration of SRT at the first sign of PSA rise. ${ }^{18}$ Moreover, such method of treatment improves the long-term outcome on patients with prostate cancer. ${ }^{19}$ In the era of ultrasensitive PSA detection, our data suggests that early administration of SRT can lead to a better oncological outcome (Figure 1). The long-term effect was not discussed in our study because the median follow up was 24 months. Further studies are needed to determine the optimal cut off of PSA at which salvage RT should be given to patients with BCR.

Moreover, the dosage of radiotherapy has always been a controversial topic. It differs among patients undergoing primary RT, ART, or SRT. With respect to our study, the dosage was 66 Gy for all 70 patients. Most studies considering early SRT have utilized on average a dosage of $66.2 \mathrm{~Gy} .{ }^{20}$ Current guidelines report that the minimum dosage that should be used in SRT is $64 \mathrm{~Gy} .{ }^{21}$ In contrast, trials evaluating adjuvant RT use dosages between 60 and $64 \mathrm{~Gy} .{ }^{22}$ In patients who undergo primary radiotherapy, a minimum dose of $>74 \mathrm{~Gy}$ is recommended for $\mathrm{RT}+\mathrm{HT}$. The European guidelines recommend a total dose of 76-78 Gy in intermediate and highrisk patients. $^{3}$

Some of the patients will experience urinary incontinence with or without impotency after radical prostatectomy. In the era of RARP, the weighted mean potency rate and the mean rate of urinary continence (no-pad) at 24 months were $64.9 \%$ and $91.4 \%$, respectively. ${ }^{9}$ In spite of the above-mentioned data, the possibility of post treatment deterioration should be addressed to the patients before initiation of radiotherapy. One of the important points highlighted in our study is that the 
functional outcome of the patients is not significantly affected with early SRT. This study has revealed that radiotherapy doesn't aggravate lower urinary tract symptoms. Strict continence, defined as the usage of 0 pads, was seen in $71 \%$ of the patients after SRT versus $78 \%$ before SRT. Hegarty et al reports that there is no significant relationship between early radiation therapy and higher rates of gastrointestinal, genitourinary, or sexual events. ${ }^{23}$ With respect to the IPSS score, the mean value after 24 months post SRT was 3.6 compared to 3.3 pre SRT. This endorses the idea that early SRT doesn't affect the patients' QOL using the IPSS score as part of the evaluation criteria. To add, another study manifested that the IPSS and QOL had returned to baseline 12 months after SRT. ${ }^{24}$

With respect to the sexual health, our study has shown that the average SHIM score was 8, 24-months post SRT compared to 8.8 pre SRT. It was stated that preoperative erectile function has an impact on recovery after RT regardless of the timing and dosage ${ }^{5} .14 \%$ had a SHIM score greater than 21 post-RT compared to $17 \%$ preRT. In our study we considered a subcategory of men with an EHS $\geq 3$ pre-RT because the average SHIM score pre-RT was low (8.83). Out of the 25 patients who had an EHS of 3 or 4 before RT, 16 patients were followed up for 2 years. Their EHS after 2 years was 3 or 4 . To add, the average SHIM score for this same subcategory was 18.32 pre-RT compared to 16.76, 24 months post-RT. Our figures eliminate the misconception that SRT causes sexual health deterioration.

Despite all this, our study has certain limitations that need to be mentioned. The number of patients undergoing SRT post RARP in the study was around 70. This number will surely increase in the coming years because of the growing number of patients undergoing RARP. The data was collected in a retrospective manner, so some of the confounders cannot be controlled. Long-term effect ( $>5$ years) was not assessed in this article, but will be addressed in future articles. Despite these limitations we believe that our results indicate that SRT post RARP is a safe procedure with valuable oncological outcomes on the patients.

This article can be the backbone of counseling men more accurately and precisely after surgery. With such data, early salvage radiotherapy can be described to the patients as a safe procedure after RARP.

\section{Conclusion}

SRT is an effective treatment for patients who experience BCR following RARP. It was shown that it improves the prognosis of the patients. This unique study has revealed that early salvage radiotherapy has a very little mid-term impact on urinary continence and potency. To note, further studies will be needed to evaluate the longterm side effects of this modality of treatment. 


\section{References}

1. Patel V. R., Sivaraman A. Current status of robot-assisted radical prostatectomy: progress is inevitable. Oncology 2012;26:616-19.

2. Abugharib, A., Jackson, W. C., Tumati, V., et al. Very early salvage radiotherapy improves distant metastasis-free survival. The Journal of Urology doi:10.1016/j.juro.2016.08.106

3. Habchi, H., \& Mottet, N. (2017). Management of prostate cancer: EAU guidelines on screening, diagnosis and local primary treatment. Management of Prostate Cancer 399-411. doi:10.1007/978-3-319-42769-0_26

4. Stish, B., Pisansky, T., Harmsen, W., et al (2016). Early salvage radiation therapy ts associated with improved metastasis-free, prostate cancer-specific and overall survival in men with detectable PSA following radical prostatectomy. International Journal of Radiation Oncology*Biology*Physics 96(2). doi:10.1016/j.ijrobp.2016.06.1218

5. Zaffuto, E., Gandaglia, G., Fossati, N., et al. (2016). Early postoperative radiotherapy is associated with worse functional outcomes in patients with prostate cancer. The Journal of Urology doi:10.1016/j.juro.2016.09.079

6. Valdivieso , R. F., Hueber, P., \& Zorn, K. (2013). Robot assisted radical prostatectomy: how I do it. Part II: Surgical technique. The Canadian Journal of Urology 20(5).

7. Ficarra V., Sooriakumaran P., Novara G., et al: Systematic review of methods for reporting combined outcomes after radical prostatectomy and proposal of a novel system: the survival, continence, and potency (SCP) classification. Eur Urol 2012; 61: pp. 541

8. Matsuda, Y., Hisasue, S., Kumamoto, Y., et al. (2014). Correlation between erection hardness score and nocturnal penile tumescence measurement. The Journal of Sexual Medicine 11(9), 2272-76. Doi:10.1111/jsm.12617

9. Zorn, K. C., Tholomier, C., Bienz, M., et al. (2014). Oncological and functional outcomes of 722 robot-assisted radical prostatectomy (RARP) cases: The largest Canadian 5-year experience. Canadian Urological Association Journal 8(5-6), 195. doi:10.5489/cuaj.2016

10. Su, M. Z., Kneebone, A. B., \& Woo, H. H. (2014). Adjuvant versus salvage radiotherapy following radical prostatectomy: do the AUA/ASTRO guidelines have all the answers? Expert Review of Anticancer Therapy 14(11), 1265-70. doi:10.1586/14737140.2014.972381

11. Herrera, F. G., \& Berthold, D. R. (2016). Radiation therapy after radical prostatectomy: Implications for clinicians. Frontiers in Oncology 6. doi:10.3389/fonc.2016.00117

12. Mizowaki, T., Aoki, M., Nakamura, K., et al. (2015). Current status and outcomes of patients developing PSA recurrence after prostatectomy who 
were treated with salvage radiotherapy: a JROSG surveillance study. Journal of Radiation Research 56(4), 750-56. doi:10.1093/jrr/rrv027

13. Van der Poel, H., Tillier, C., de Blok, et al. (2013). Salvage radiotherapy after robot-assisted laparoscopic radical prostatectomy. Urology 82(4), 834-839. http://dx.doi.org/10.1016/j.urology.2013.04.057

14. Kwon, O., Kim, K. B., Lee, et al. (2014). Salvage Radiotherapy after radical prostatectomy: Prediction of biochemical outcomes. Plos One 9(7). doi:10.1371/journal.pone.0103574

15. Pfister, D., Bolla, M., Briganti, A., et al. (2014). Early salvage radiotherapy following radical prostatectomy. European Urology 65(6), 1034-1043. doi:10.1016/j.eururo.2013.08.013

16. Gandaglia, G., Karakiewicz, P. I., Briganti, A., et al. (2014). Early radiotherapy after radical prostatectomy improves cancer-specific survival only in patients with highly aggressive prostate cancer: Validation of recently released criteria. International Journal of Urology 22(1), 89-95. doi:10.1111/iju.12605

17. Tendulkar, R., Agrawal, S., Efstathiou, J., et al. (2015). Contemporary update of a multi-institutional predictive nomogram for salvage radiation therapy after prostatectomy. International Journal of Radiation Oncology*Biology*Physics 93(3). doi:10.1016/j.ijrobp.2015.07.313

18. Fossati, N., Karnes, R. J., Cozzarini, C., et al. (2016). Assessing the optimal timing for early salvage radiation therapy in patients with prostate-specific antigen rise after radical prostatectomy. European Urology 69(4), 728-733. doi:10.1016/j.eururo.2015.10.009

19. Gandaglia, G., Cozzarini, C., Mottrie, A., et al. (2015). The role of radiotherapy after radical prostatectomy in patients with prostate cancer. Current Oncology Reports 17(12). doi:10.1007/s11912-015-0478-5

20. Briganti, A., Wiegel, T., Joniau, S., et al. (2012). Early salvage radiation therapy does not compromise cancer control in patients with pT3N0 prostate cancer after radical prostatectomy: Results of a match-controlled multiinstitutional analysis. European Urology 62(3), 472-487. doi:10.1016/j.eururo.2012.04.056

21. Valicenti, R. K., Thompson, I., Albertsen, P., et al. (2013). Adjuvant and salvage radiation therapy after prostatectomy: American society for radiation oncology/American rrological association guidelines. International Journal of Radiation Oncology*Biology*Physics 86(5), 822-828. doi:10.1016/j.ijrobp.2013.05.029

22. Thompson, I. M., Tangen, C. M., Paradelo, J., et al. (2006). Adjuvant radiotherapy for pathologically advanced prostate cancer. Jama 296(19), 2329. doi:10.1001/jama.296.19.2329

23. Hegarty, S. E., Hyslop, T., Dicker, A. P., et al. (2015). Radiation therapy after radical prostatectomy for prostate cancer: Evaluation of complications and 
influence of radiation timing on outcomes in a large, population-based cohort. Plos One 10(2). doi:10.1371/journal.pone.0118430

24. Miyake, M., Tanaka, N., Asakawa, I., et al. (2015). Changes in lower urinary tract symptoms and quality of life after salvage radiotherapy for biochemical recurrence of prostate cancer. Radiotherapy and Oncology 115(3), 321-326. doi:10.1016/j.radonc.2015.04.026 


\section{Figures and Tables}

Fig. 1. Kaplan-Meier curve for patients with a pre-radiotherapy (RT) prostate-specific antigen (PSA) of $<0.2 \mathrm{ng} / \mathrm{ml}$ and $\geq 0.2 \mathrm{ng} / \mathrm{ml}$.

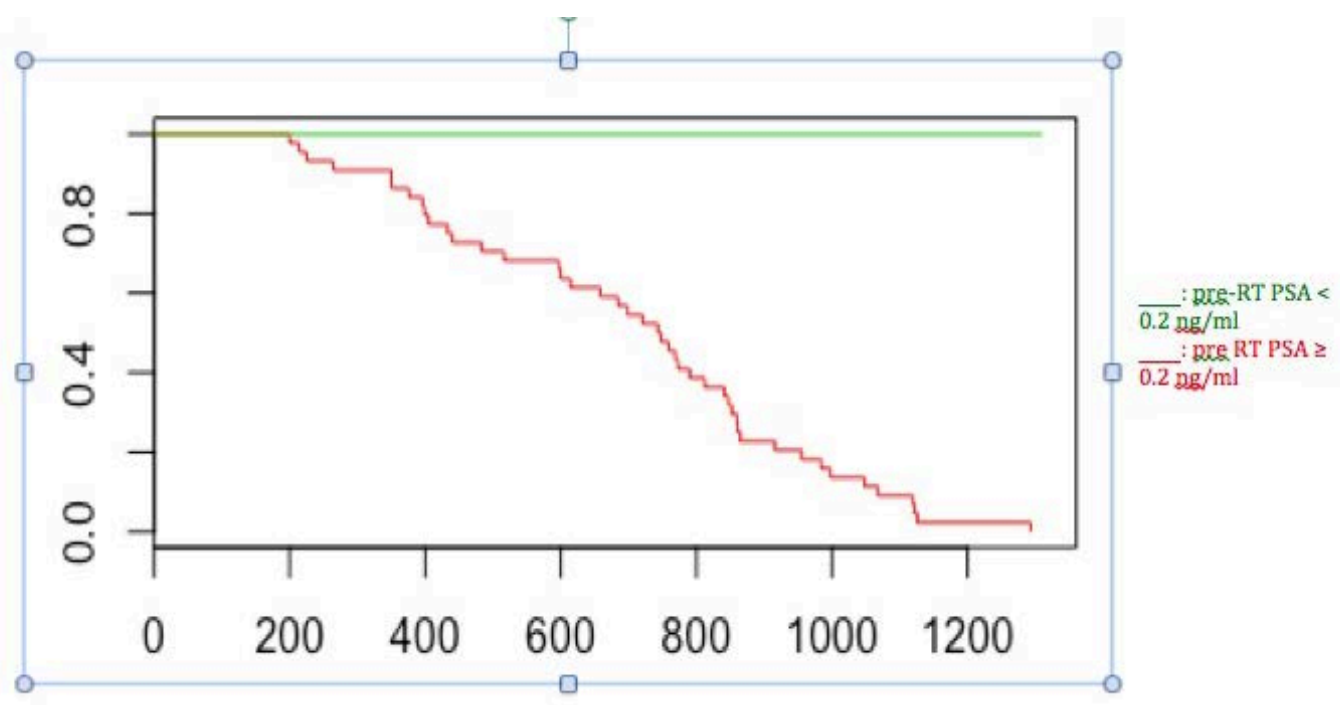

\begin{tabular}{|c|c|c|c|c|}
\hline & $\begin{array}{c}\text { Overall } \\
(n=70)\end{array}$ & $\begin{array}{l}\text { PSA }<0.2 \text { at } \\
\text { SRT }(n=26)\end{array}$ & $\begin{array}{l}\text { PSA } \geq 0.2 \text { at } \\
\text { SRT }(n=44)\end{array}$ & $\mathbf{p}$ \\
\hline Age (years) & $\begin{array}{c}61.86(60.15- \\
63.57) \\
\end{array}$ & $\begin{array}{c}61.58(58.99- \\
64.16)\end{array}$ & $\begin{array}{c}62.02(59.69- \\
64.35)\end{array}$ & 0.43 \\
\hline BMI $\left(\mathrm{kg} / \mathrm{m}^{2}\right)$ & $\begin{array}{c}27.84(26.74- \\
28.94)\end{array}$ & $\begin{array}{c}27.60(25.33- \\
29.86)\end{array}$ & $\begin{array}{c}27.99(26.81- \\
29.18)\end{array}$ & 0.28 \\
\hline CAPRA-S score & $4.14(2.18-6.11)$ & $\begin{array}{c}4.04(3.25- \\
4.83)\end{array}$ & $\begin{array}{c}4.20(3.73- \\
4.68)\end{array}$ & 0.61 \\
\hline PSADT (months) & $\begin{array}{c}15.97(11.97- \\
19.97)\end{array}$ & $\begin{array}{l}22.16(13.16- \\
31.16)\end{array}$ & $\begin{array}{c}12.31(8.89- \\
15.72)\end{array}$ & 0.09 \\
\hline Pre-RARP PSA (ng/dl) & $8.53(7.36-9.71)$ & $\begin{array}{c}8.01(5.99- \\
10.01)\end{array}$ & $\begin{array}{c}8.84(7.35- \\
10.33)\end{array}$ & 0.02 \\
\hline Pre-RT PSA (ng/ml) & $0.50(0.21-0.79)$ & $\begin{array}{c}0.14(0.13- \\
0.16)\end{array}$ & $\begin{array}{c}0.75(0.29- \\
1.22)\end{array}$ & 0.01 \\
\hline $\begin{array}{l}\text { Mean time between RARP } \\
\text { and RT (days) }\end{array}$ & 458 (307-747) & 518 (402-635) & 398 (277-519) & 0.28 \\
\hline \multicolumn{5}{|l|}{$\begin{array}{l}\text { Surgical pathology } \\
\text { details } \\
\text { pT - stage (\%) }\end{array}$} \\
\hline pT2 & $26(37.14)$ & 11 & 15 & 0.49 \\
\hline pT3a & $32(45.71)$ & 12 & 20 & 0.16 \\
\hline pT3b & $12(15.71)$ & 3 & 9 & 0.13 \\
\hline
\end{tabular}




\begin{tabular}{|c|c|c|c|c|}
\hline \multicolumn{5}{|l|}{$\begin{array}{l}\text { Pathological Gleason } \\
\text { score (\%) }\end{array}$} \\
\hline 6 & $4(5.71)$ & 1 & 3 & 0.27 \\
\hline $7(3+4)$ & 27 (38.57) & 10 & 17 & 0.18 \\
\hline $7(4+3)$ & $17(24.29)$ & 8 & 9 & 0.81 \\
\hline $8-10$ & $22(31.43)$ & 7 & 15 & 0.09 \\
\hline \multicolumn{5}{|l|}{$\begin{array}{l}\text { Positive surgical margins } \\
\text { (\%) } \\
\text { Overall }\end{array}$} \\
\hline $\mathrm{pT} 2$ & 15 & 8 & 7 & 0.98 \\
\hline pT3 & 32 & 10 & 22 & 0.82 \\
\hline \multicolumn{5}{|l|}{$\begin{array}{l}\text { Nerve-sparing (NS) } \\
\text { technique (\%) }\end{array}$} \\
\hline Bilateral NS & 34 (48.57) & 13 & 21 & 0.62 \\
\hline Unilateral NS & $11(15.71)$ & 2 & 9 & 0.43 \\
\hline Non-nerve-sparing & $25(35.71)$ & 11 & 14 & 0.67 \\
\hline
\end{tabular}

BMI: body mass index; CAPRA-S: Cancer of the Prostate Risk Assessment score; PSA: prostate-specific antigen; PSADT: PSA doubling time; RARP: robot-assisted radical prostatectomy; $\mathrm{RT}$ : radiotherapy.

\begin{tabular}{|c|c|c|c|}
\hline Time (months) & $\begin{array}{c}\text { Continent: } 0 \text { pads } \\
\text { or } 1 \text { security pad, } \\
\text { n ( } \%)\end{array}$ & $\begin{array}{c}\text { Incontinent } \\
\geq 1 \text { pad, } \\
\text { n }(\%)\end{array}$ & $\begin{array}{c}\text { Total number } \\
\text { of patients }\end{array}$ \\
\hline Pre-RT & $55(78.57)$ & $15(21.43)$ & 70 \\
\hline 6 & $54(81.82)$ & $12(18.18)$ & 66 \\
\hline 12 & $46(75.41)$ & 15 (24.59) & 61 \\
\hline 24 & $37(71.15)$ & $15(28.85)$ & 52 \\
\hline & IPSS & CI & $\mathbf{p}$ \\
\hline Pre-RT & 3.39 & (2.79-3.97) & \\
\hline 6 & 3.44 & $(2.67-4.21)$ & 0.9121 \\
\hline 12 & 3.62 & $(2.72-4.51)$ & 0.6666 \\
\hline \multirow[t]{2}{*}{24} & 3.66 & $(2.75-4.57)$ & 0.6123 \\
\hline & QOL score & CI & $\mathbf{p}$ \\
\hline Pre-RT & 1.62 & $(1.05-2.19)$ & \\
\hline 6 & 1.70 & $(1.22-2.18)$ & 0.8214 \\
\hline 12 & 1.61 & $(0.97-2.25)$ & 0.9846 \\
\hline 24 & 1.61 & $(0.86-2.36)$ & 0.9859 \\
\hline
\end{tabular}

CI: confidence interval; IPSS: International Prostate Symptom Score; QOL: quality of life; RT: radiotherapy. 


\begin{tabular}{|c|c|c|c|c|c|c|}
\hline $\begin{array}{l}\text { Time } \\
\text { (months) }\end{array}$ & \multicolumn{2}{|c|}{$\begin{array}{c}\text { EHS } \leq 2 \\
\text { n (\%) }\end{array}$} & \multicolumn{2}{|c|}{$\begin{array}{c}\text { EHS }>2, \\
\text { n }(\%)\end{array}$} & \multicolumn{2}{|c|}{$\begin{array}{c}\text { Total number of } \\
\text { patients }\end{array}$} \\
\hline Pre-RT & \multicolumn{2}{|c|}{45 (64.29) } & \multicolumn{2}{|c|}{25 (35.71) } & \multicolumn{2}{|c|}{70} \\
\hline 6 & \multicolumn{2}{|c|}{$41(65.08)$} & \multicolumn{2}{|c|}{$22(34.92)$} & \multicolumn{2}{|c|}{63} \\
\hline 12 & \multicolumn{2}{|c|}{$36(63.07)$} & \multicolumn{2}{|c|}{$22(37.93)$} & \multicolumn{2}{|c|}{58} \\
\hline 24 & \multicolumn{2}{|c|}{31 (64.58) } & \multicolumn{2}{|c|}{$17(35.42)$} & \multicolumn{2}{|c|}{48} \\
\hline $\begin{array}{l}\text { Time } \\
\text { (months) }\end{array}$ & $\begin{array}{c}\text { SHIM } \\
\text { score }<21 \text {, } \\
\text { n }(\%)\end{array}$ & $\begin{array}{c}\text { SHIM } \\
\text { score } \geq 21, \\
\text { n (\%) }\end{array}$ & $\begin{array}{c}\text { Total } \\
\text { number } \\
\text { of } \\
\text { patients }\end{array}$ & Mean & Mean CI & $\mathbf{p}$ \\
\hline Pre-RT & $\begin{array}{c}58 \\
(82.86)\end{array}$ & $12(17.14)$ & 70 & 8.823 & $(6.89-10.76)$ & \\
\hline 6 & $\begin{array}{c}57 \\
(81.43)\end{array}$ & $13(18.57)$ & 70 & 11.07 & $(9.25-12.89)$ & 0.09335 \\
\hline 12 & $\begin{array}{c}51 \\
(86.44)\end{array}$ & $8(13.56)$ & 59 & 8.32 & $(6.22-10.42)$ & 0.7247 \\
\hline 24 & $43(86)$ & $7(14)$ & 50 & 8.18 & $(5.88-10.48)$ & 0.6669 \\
\hline
\end{tabular}

CI: confidence interval; EHS: erection hardness score; SHIM: Sexual Health Inventory for Men; RT: radiotherapy. 